\title{
Fixed-Dose Triple Combination of Antihypertensive Drugs Improves Blood Pressure Control: From Clinical Trials to Clinical Practice
}

\author{
Alberto Mazza · Salvatore Lenti · Laura Schiavon · Antonella Paola Sacco • \\ Fabio Dell'Avvocata · Gianluca Rigatelli · Emilio Ramazzina
}

Received: February 2, 2017 / Published online: March 15, 2017

(C) The Author(s) 2017. This article is published with open access at Springerlink.com

\begin{abstract}
Introduction: Blood pressure (BP) control is the main clinical goal in the management of hypertensive patients; however, BP in most of these patients remains uncontrolled, despite the widespread availability of antihypertensive drugs as free-combination therapy. This study compared the efficacy of a fixed-dose triple combination (FDTC) of antihypertensive drugs with that of a free combination of three antihypertensives in patients with uncontrolled hypertension.
\end{abstract}

Enhanced content To view enhanced content for this article go to http://www.medengine.com/Redeem/ B4F7F0607F39B617.

A. Mazza ( $\square)$

Hypertension Centre Certified by the Italian Society of Hypertension, S. Maria della Misericordia

Hospital, AULSS 5 Polesana, Rovigo, Italy

e-mail: alberto.mazza@aulss5.veneto.it

S. Lenti

Hypertension Centre and Internal Medicine and Geriatrics, San Donato Hospital, USL 8, Arezzo, Italy

L. Schiavon - A. P. Sacco · E. Ramazzina

Department of Medicine, S. Maria della Misericordia

Hospital, AULSS 5 Polesana, Rovigo, Italy

F. Dell'Avvocata · G. Rigatelli

Interventional Cardiology Unit, Division of

Cardiology, S. Maria della Misericordia Hospital,

AULSS 5 Polesana, Rovigo, Italy
Methods: Ninety-two patients (mean age $60.8 \pm$ $12.1,58.0 \%$ male) with uncontrolled essential hypertension (office systolic BP $\geq 140$ or diastolic $\mathrm{BP} \geq 90 \mathrm{mmHg}$ ) previously treated with a renin-angiotensin-aldosterone system (RAAS) inhibitor plus hydrochlorothiazide were switched to once-daily FDTC therapy with perindopril/indapamide/amlodipine (5-10/1.25-2.5/ 5-10 mg). Patients were age- and sex-matched with a control group of hypertensive patients receiving free-combination therapy with three drugs including a RAAS inhibitor, a diuretic, and a calcium channel blocker. Office BP and 24-h ambulatory BP monitoring (ABPM) were evaluated at baseline and after 1 and 4 months.

Results: Significant reductions in ambulatory 24-h, daytime, and nighttime systolic BP, and pulse pressure (PP) were found in the FDTC group relative to reductions seen with free-combination therapy, after the first month only of follow-up. Target BP values (mean 24-h ambulatory systolic/diastolic $\mathrm{BP}<130$ / $80 \mathrm{mmHg}$ ) were reached by more recipients of FDTC than free-combination therapy (64.8\% vs. $46.9 \%, p<0.05)$ at month 4 of follow-up, despite reductions in 24-h ABPM values from baseline being similar in both groups at this time point.

Conclusion: FDTC of perindopril/indapamide/ amlodipine was effective at reducing SBP and PP in previously treated patients with uncontrolled hypertension, and well tolerated, providing support for clinicians in choosing a fixed-dose 
triple combination over the free-combination of a RAAS inhibitor, a diuretic, and a calcium antagonist.

Keywords: Amlodipine; Antihypertensives; Hypertension; Indapamide; Perindopril; Target blood pressure; Triple fixed-dose combination

\section{INTRODUCTION}

Despite the widespread availability of effective antihypertensive drugs, in the majority of hypertensive patients blood pressure remains uncontrolled and, in most countries, at least $50 \%$ of hypertensive patients do not achieve currently recommended blood pressure targets [1]. In this respect, clinical trials have shown that adequate blood pressure control is possible with combinations of up to four antihypertensive drugs [2-4]. American and European guidelines for the treatment of hypertension suggest $[5,6]$, as initial therapy, the option of a combination of two antihypertensive drugs to achieve better control and, if hypertension remains uncontrolled, the addition of a third antihypertensive drug is recommended [5].

In addition to the potential benefits of combining different drug classes owing to their possible synergistic pharmacological and physiological actions, this approach-in particular if provided at fixed doses in a single pill-also improves patient compliance to treatment $[7,8]$. This strategy seems more effective than the separate administration of two or more antihypertensive agents (free-drug combination), not only in blood pressure control but also in promoting decreased cardiovascular events [9], hospitalization rates [10], and costs [11]. Although many studies have been performed comparing fixed-dose combinations with single agents [10, 12], data comparing fixed-dose and free-drug combinations are limited.

In this study, the efficacy and safety of a fixed-dose triple combination (FDTC) of antihypertensive drugs given as a single pill were compared with the use of free-drug combinations in the treatment of hypertension.

\section{METHODS}

The aim of the study was to evaluate the efficacy and tolerability of the FDTC vs. free-combination therapy in lowering office and 24-h BP values.

\section{Patients}

This interventional study included grade 2 (defined as SBP 160-179 mmHg and/or DBP 100$109 \mathrm{mmHg}$ ) hypertensive patients with uncontrolled hypertension despite previously receiving dual fixed-combination antihypertensive therapy including a renin-angiotensin-aldosterone system (RAAS) inhibitor plus a diuretic.

Exclusion criteria were a history of cardiovascular events, severe hypertension (office $\mathrm{SBP} \geq 180 \mathrm{mmHg}$ or $\mathrm{DBP} \geq 110 \mathrm{mmHg}$, secondary hypertension, neoplastic or hepatic diseases, chronic heart or renal failure, positive history or clinical signs of ischemic heart disease, severe obesity (body weight $>150 \%$ of the ideal), disabling diseases such as dementia or inability to cooperate, pregnancy, or breast-feeding.

The study protocol was approved by local ethics committee and institutional review boards, and procedures were followed in accordance with ICH Harmonized Tripartite Guidelines for Good Clinical Practice and with the Helsinki Declaration of 1964, as revised in 2013. Informed consent was obtained from all patients for being included in the study. Patients could discontinue the study at any time and for any reason, and treatment was stopped if a serious adverse event occurred.

\section{Study Design}

Consecutive patients were initially screened for inclusion criteria and patients still meeting criteria after a 4-week run-in period were enrolled in the FDTC treatment group and received perindopril/indapamide/amlodipine at doses ranging from $5 / 1.25 / 5$ to $10 / 2.5 / 10 \mathrm{mg}$ once daily in the morning for 4 months. An age- and sex-matched control group of hypertensive patients was screened and enrolled to receive a 
free-combination of three antihypertensive agents including a RAAS blocker, a diuretic, and a calcium channel blocker. Study drug dosages in both arms were determined according to baseline arterial BP. The pressor target was defined as office-assessed SBP/DBP $<140 /$ $90 \mathrm{mmHg}$, and an ambulatory blood pressure monitoring (ABPM)-assessed $\mathrm{SBP} / \mathrm{DBP}<130 /$ $80 \mathrm{mmHg}$.

\section{Data Collection}

Office and 24-h blood pressure values were evaluated at baseline and at month 1 and 4 of follow-up. Office blood pressure (diastolic Korotkoff phase 5) was measured in triplicate in the prone position using a mercury sphygmomanometer at 10-min intervals, taking care to avoid any terminal digit preference [6], and the average of the last two clinostatic measurements was recorded as the blood pressure. Heart rate was also taken at the same time. Pulse pressure was the difference between SBP and DBP. Arterial hypertension was defined as SBP $\geq 140 \mathrm{mmHg}$ or DBP $\geq 90 \mathrm{mmHg}$. In all patients, clinic hypertension was confirmed with 24-h ABPM using an oscillometric device (TM-2430, Takeda, Japan) applied to the non-dominant arm [13].

Body mass index (BMI) was calculated as the ratio of weight (in kilograms) to squared height (in meters). Patients were classified as never or current ( $\geq 1$ cigarette daily) smokers. Laboratory parameter monitoring included serum potassium and creatinine levels. Fasting serum creatinine (in $\mathrm{mg} / \mathrm{dl}$ ) was measured by Jaffé's alkaline picrate kinetic method [14] using an autoanalyzer (Hitachi Modular P, Roche diagnostic, USA).

Adherence to medication was measured indirectly through patient self-reports and pill counts.

\section{Statistical Analyses}

Continuous variables were expressed as mean and standard deviation, and compared with analysis of variance and Bonferroni's post hoc test. The Chi-square test was used for comparisons between categorical variables. Analysis of variance for repeated measures compared changes of different blood pressure components and serum lipids at baseline and at follow-up visits; differences between continuous variables were evaluated in the two groups with Tukey's post hoc test. All statistical analyses were performed using the SPSS package version 17.0 for Windows (SPSS, Chicago, IL, USA). The null hypothesis was always rejected for $p<0.05$.

\section{RESULTS}

Ninety-two patients (54 men and 38 women, mean age $60.8 \pm 12.1$ years), age- and sex-matched by the case-to-case method with a control group of 92 patients, were evaluated. Consecutive patients had been screened and eligible patients enrolled between October 2015 and June 2016 in our Hypertension Centre of the Rovigo General Hospital. The general characteristics of the two treatment groups at baseline are summarized in Table 1 . Mean age was $60.8 \pm 12.1$ years in the whole study group $(59.4 \pm 11.5$ in men and $63.8 \pm$ 13.9 in women, $p<0.001)$. Mean \pm SD office BP at baseline was similar between study arms (DBP $153.2 \pm 11.8$ vs. $154.6 \pm 13.0 \mathrm{mmHg} ; \quad$ SBP $95.1 \pm 5.3$ vs. $94.0 \pm 6.7 \mathrm{mmHg}$ in the fixed vs free combination groups, respectively.

\section{Intervention}

The antihypertensive potency of antihypertensive therapy administered was based on office BP at baseline. The distribution of dosages in the group receiving a fixed combination of perindopril/indapamide/amlodipine (in increasing order of potency) was $5 / 1.25 / 5 \mathrm{mg}$ in $42.4 \%$ of patients, $5 / 1.25 / 10 \mathrm{mg}$ in $2.2 \%, 10.2 .5 / 5 \mathrm{mg}$ in $25 \%$, and $10 / 2.5 / 10 \mathrm{mg}$ in $30.4 \%$. The distribution of antihypertensive potency was comparable in the free-combination group.

In the free-combination group, RAAS inhibition was accomplished with angiotensin-converting enzyme inhibitors (ACEIs) in $65 \%$ of patients (of which, ramipril $40 \%$, perindopril $30 \%$, enalapril $25 \%$, others $5 \%$ ); whereas angiotensin II receptor blockers (ARBs) were used in $35 \%$ (of which, valsartan 35\%, olmesartan $25 \%$, telmisartan $20 \%$, losartan $15 \%$, others $5 \%$ ); diuretics were hydrochlorothiazide $75 \%$ or indapamide $25 \%$. 
Table 1 General characteristics of the study population at baseline

\begin{tabular}{|c|c|c|c|c|}
\hline & All patients $(n=184)$ & FDTC $(n=92)$ & FCT $(n=92)$ & $p$ value \\
\hline Age, years & $60.8 \pm 12.1$ & $61.4 \pm 11.8$ & $60.1 \pm 12.5$ & NS \\
\hline Male, \% & 58.0 & 56.8 & 65.0 & NS \\
\hline Body mass index, $\mathrm{kg} / \mathrm{m}^{2}$ & $28.5 \pm 4.9$ & $28.1 \pm 4.7$ & $28.9 \pm 5.1$ & NS \\
\hline \multicolumn{5}{|l|}{ Clinic BP values } \\
\hline $\mathrm{SBP}, \mathrm{mmHg}$ & $153.7 \pm 12.6$ & $153.2 \pm 11.8$ & $154.6 \pm 13.0$ & NS \\
\hline DBP, $\mathrm{mmHg}$ & $94.5 \pm 6.0$ & $95.1 \pm 5.3$ & $94.0 \pm 6.7$ & NS \\
\hline $\mathrm{PP}, \mathrm{mmHg}$ & $59.2 \pm 11.2$ & $58.1 \pm 10.3$ & $60.6 \pm 12.1$ & NS \\
\hline \multicolumn{5}{|l|}{ 24-h ABPM values } \\
\hline 24-h SBP, mmHg & $144.2 \pm 9.7$ & $144.8 \pm 8.9$ & $143.6 \pm 10.8$ & NS \\
\hline 24-h DBP, mmHg & $86.0 \pm 6.9$ & $85.3 \pm 7.2$ & $86.8 \pm 6.5$ & NS \\
\hline 24-h PP, mmHg & $58.1 \pm 7.6$ & $59.5 \pm 7.2$ & $56.8 \pm 8.1$ & NS \\
\hline Daytime SBP, mmHg & $147.5 \pm 9.8$ & $147.2 \pm 9.1$ & $148.0 \pm 10.9$ & NS \\
\hline Daytime DBP, mmHg & $91.7 \pm 6.3$ & $92.4 \pm 5.5$ & $90.1 \pm 7.1$ & NS \\
\hline Daytime PP, mmHg & $55.8 \pm 7.4$ & $54.8 \pm 7.9$ & $57.8 \pm 8.3$ & NS \\
\hline Nighttime SBP, mmHg & $129.6 \pm 10.0$ & $128.9 \pm 9.3$ & $130.5 \pm 10.5$ & NS \\
\hline Nighttime DBP, mmHg & $77.0 \pm 6.8$ & $77.6 \pm 7.3$ & $76.4 \pm 6.1$ & NS \\
\hline Nighttime PP, mmHg & $52.6 \pm 6.3$ & $51.3 \pm 5.9$ & $54.1 \pm 7.2$ & NS \\
\hline $\mathrm{TC}, \mathrm{mg} / \mathrm{dl}$ & $198.1 \pm 23.6$ & $200.2 \pm 18.3$ & $196.8 \pm 29.3$ & NS \\
\hline LDL-C, mg/dl & $123.5 \pm 23.6$ & $124.3 \pm 21.2$ & $122.8 \pm 26.9$ & NS \\
\hline HDL-C, mg/dl & $52.9 \pm 13.0$ & $51.4 \pm 12.7$ & $53.3 \pm 13.8$ & NS \\
\hline Triglycerides, mg/dl & $101.4 \pm 40.2$ & $99.7 \pm 33.5$ & $103.4 \pm 46.8$ & NS \\
\hline Glucose, $\mathrm{mg} / \mathrm{dl}$ & $99.7 \pm 11.3$ & $98.4 \pm 8.3$ & $100.8 \pm 14.4$ & NS \\
\hline Creatinine, $\mathrm{mg} / \mathrm{dl}$ & $1.0 \pm 0.2$ & $1.1 \pm 0.1$ & $1.0 \pm 0.3$ & NS \\
\hline Potassium, mg/dl & $4.28 \pm 0.27$ & $4.17 \pm 0.31$ & $4.36 \pm 0.22$ & NS \\
\hline Diabetes, \% & 11.9 & 10.2 & 13.6 & NS \\
\hline Smokers, \% & 19.8 & 17.0 & 20.1 & NS \\
\hline
\end{tabular}

Values are presented as patient numbers and percentages or means \pm standard deviations $A B P M$ ambulatory blood pressure monitoring, $D B P$ diastolic blood pressure, $H D L$ - $C$ high density lipoprotein, $F C T$ free-combination, $F D T C$ fixed-dose triple combination, $L D L-C$ low density lipoprotein cholesterol, $N S$ not significant, $P P$ pulse pressure, $S B P$ systolic blood pressure, $T C$ total cholesterol

In both treatment groups, significant reductions in ABPM values were observed at month 4 of follow-up, relative to baseline (Tables 2, 3). At the first month of follow-up, significant reductions from baseline in ambulatory 24-h, daytime, and nighttime SBP were found in the FDTC group (11.6, 16, and $11.4 \mathrm{mmHg}$, respectively) relative to reductions seen with 
Table 2 Differences for office and ambulatory values in the group treated with fixed-dose triple combination antihypertensive therapy

\begin{tabular}{lccccc}
\hline & $\begin{array}{l}\text { Baseline } \\
(\boldsymbol{n}=\mathbf{9 2})\end{array}$ & $\begin{array}{l}\text { 1st month } \\
(\boldsymbol{n}=\mathbf{9 2})\end{array}$ & $\begin{array}{c}\text { 4th month } \\
(\boldsymbol{n}=\mathbf{8 9})\end{array}$ & $\boldsymbol{F}$ & $\begin{array}{c}\boldsymbol{p} \text { value } \\
\text { for trend }\end{array}$ \\
\hline Office values & & & & & \\
SBP, mmHg & $154.6 \pm 13.0$ & $139.3 \pm 8.1$ & $132.2 \pm 5.1$ & 137.0 & 0.0001 \\
DBP, mmHg & $94.0 \pm 7.0$ & $84.5 \pm 6.7$ & $82.9 \pm 4.8$ & 139.9 & 0.0001 \\
PP, mmHg & $60.6 \pm 12.1$ & $54.8 \pm 7.3$ & $50.3 \pm 5.6$ & 30.7 & 0.0001 \\
HR, bpm & $74.3 \pm 6.9$ & $73.3 \pm 5.9$ & $74.2 \pm 4.5$ & 1.0 & 0.413 \\
ABPM values & & & & \\
24-h SBP, mmHg & $143.6 \pm 10.8$ & $132.0 \pm 8.1$ & $125.5 \pm 5.6$ & 82.9 & 0.001 \\
24-h DBP, mmHg & $86.8 \pm 6.5$ & $79.8 \pm 4.6$ & $77.9 \pm 3.9$ & 57.8 & 0.0001 \\
24-h PP, mmHg & $56.8 \pm 8.1$ & $52.2 \pm 6.7$ & $50.6 \pm 3.4$ & 25.2 & 0.001 \\
24-h HR, bpm & $72.7 \pm 6.6$ & $72.9 \pm 6.3$ & $73.2 \pm 4.5$ & 1.4 & 0.748 \\
Daytime SBP, mmHg & $148.0 \pm 10.9$ & $132.0 \pm 8.1$ & $128.5 \pm 3.6$ & 128.9 & 0.0001 \\
Daytime DBP, mmHg & $90.1 \pm 7.1$ & $83.1 \pm 4.9$ & $78.0 \pm 3.9$ & 110.1 & 0.0001 \\
Daytime PP, mmHg & $57.8 \pm 8.3$ & $52.2 \pm 6.7$ & $50.6 \pm 3.4$ & 33.5 & 0.0001 \\
Daytime HR, bpm & $75.1 \pm 6.7$ & $72.9 \pm 6.3$ & $73.2 \pm 4.6$ & 6.9 & 0.392 \\
Nighttime SBP, mmHg & $130.5 \pm 10.5$ & $119.1 \pm 7.7$ & $116.1 \pm 4.0$ & 78.7 & 0.0001 \\
Nighttime DBP, mmHg & $76.4 \pm 6.1$ & $69.3 \pm 4.9$ & $66.1 \pm 3.8$ & 94.9 & 0.0001 \\
Nighttime PP, mmHg & $54.1 \pm 7.2$ & $50.0 \pm 5.9$ & $50.3 \pm 3.6$ & 13.9 & 0.0001 \\
Nighttime HR, bpm & $67.0 \pm 6.6$ & $66.5 \pm 5.4$ & $68 \pm 3.9$ & 3.1 & 0.055 \\
\hline Vas & & & &
\end{tabular}

Values are presented as means \pm standard deviations

$A B P M$ ambulatory blood pressure monitoring, $D B P$ diastolic blood pressure, $H R$ heart rate, $P P$ pulse pressure, $S B P$ systolic blood pressure

free-combination therapy $(6.9,5.5$, and $4.8 \mathrm{mmHg} ; p<0.0001$ ) (Fig. 1). Reductions from baseline in ambulatory 24-h, daytime, and nighttime pulse pressures were also significantly greater with FDTC therapy (Fig. 1). However, at month 4 of follow-up, there were no significant differences in reductions from baseline between the two groups. The change from baseline in ABPM-assessed DBP was not significantly different between groups during the entire follow-up period (Fig. 1).

Both office and ABPM-assessed heart rate values were essentially unchanged.

Office SBP/DBP significantly was reduced from baseline to month 4 in both groups, but between-group values were similar (by 22.4/ $11.1 \mathrm{mmHg}$ at month 4 in the FDTC group and by $18.9 / 11.7 \mathrm{mmHg}$ in the free-combination group, both $p<0.0001$ for trend).

At the end of the first month, target office blood pressure was reached by $70.5 \%$ of patients on FDTC and by $66.4 \%$ of those on free-combination therapy $(p=0.21)$, and at the end of the fourth month by $75.6 \%$ and $71.2 \%$, respectively $(p<0.34)$. When target 24 -h ABPM was evaluated, the response rate to the treatment was significantly higher in the FDTC than the free-combination therapy group, both at month $1(45.3 \%$ vs. $32.8 \%, p<0.05)$ and at 
Table 3 Differences for office and ambulatory values in the group treated with a free combination of three antihypertensives

\begin{tabular}{lccccc}
\hline & $\begin{array}{l}\text { Baseline } \\
(\boldsymbol{n}=\mathbf{9 2})\end{array}$ & $\begin{array}{l}\text { 1st month } \\
(\boldsymbol{n}=\mathbf{9 2})\end{array}$ & $\begin{array}{c}\text { 4th month } \\
(\boldsymbol{n}=\mathbf{9 0})\end{array}$ & $\boldsymbol{F}$ & $\begin{array}{c}\boldsymbol{p} \text { value } \\
\text { by trend }\end{array}$ \\
\hline Office values & & & & & \\
SBP, mmHg & $153.2 \pm 11.8$ & $140.1 \pm 7.3$ & $134.3 \pm 4.1$ & 126.0 & 0.0001 \\
DBP, mmHg & $95.1 \pm 5.3$ & $85.4 \pm 8.3$ & $83.4 \pm 5.6$ & 132.4 & 0.0001 \\
PP, mmHg & $58.1 \pm 10.3$ & $56.7 \pm 6.1$ & $50.9 \pm 4.8$ & 27.2 & 0.0001 \\
HR, bpm & $73.4 \pm 8.1$ & $74.8 \pm 7.3$ & $75.2 \pm 5.3$ & 4.2 & 0.523 \\
ABPM values & & & & \\
24-h SBP, mmHg & $144.8 \pm 8.9$ & $137.9 \pm 7.5$ & $127.3 \pm 6.4$ & 93.2 & 0.001 \\
24-h DBP, mmHg & $85.3 \pm 7.2$ & $81.8 \pm 6.3$ & $78.6 \pm 4.8$ & 78.6 & 0.0001 \\
24-h PP, mmHg & $59.5 \pm 7.2$ & $56.1 \pm 6.7$ & $48.7 \pm 5.1$ & 53.2 & 0.001 \\
24-h HR, bpm & $78.9 \pm 8.2$ & $80.1 \pm 6.9$ & $79.6 \pm 5.7$ & 3.6 & 0.416 \\
Daytime SBP, mmHg & $147.2 \pm 9.1$ & $141.7 \pm 5.9$ & $130.0 \pm 4.8$ & 132.4 & 0.0001 \\
Daytime DBP, mmHg & $92.4 \pm 5.5$ & $85.8 \pm 5.7$ & $81.2 \pm 5.7$ & 116.8 & 0.0001 \\
Daytime PP, mmHg & $54.8 \pm 7.9$ & $55.9 \pm 7.4$ & $48.8 \pm 4.1$ & 41.6 & 0.0001 \\
Daytime HR, bpm & $82.3 \pm 6.8$ & $79.4 \pm 5.6$ & $80.6 \pm 6.2$ & 11.2 & 0.228 \\
Nighttime SBP, mmHg & $128.9 \pm 9.3$ & $124.1 \pm 8.2$ & $118.2 \pm 7.4$ & 64.5 & 0.0001 \\
Nighttime DBP, mmHg & $77.6 \pm 7.3$ & $70.4 \pm 6.1$ & $69.1 \pm 8.2$ & 87.2 & 0.0001 \\
Nighttime PP, mmHg & $51.3 \pm 5.9$ & $53.7 \pm 3.6$ & $49.1 \pm 4.3$ & 15.4 & 0.0001 \\
Nighttime HR, bpm & $70.2 \pm 7.8$ & $69.7 \pm 6.2$ & $71.6 \pm 5.7$ & 8.9 & 0.356 \\
\hline Vals & & & &
\end{tabular}

Values are presented as means \pm standard deviations

$A B P M$ ambulatory blood pressure monitoring, $D B P$ diastolic blood pressure, $H R$ heart rate, $P P$ pulse pressure, $S B P$ systolic blood pressure

month 4 of follow-up $(64.8 \%$ vs. $46.9 \%$, $p<0.05$ ).

Mean changes in serum potassium values from baseline to month 4 of follow-up were greater in the FDTC group (from $4.36 \pm 0.22 \mathrm{vs}$. $3.97 \pm 0.26$ [month 1] to $3.89 \pm 0.21 \mathrm{mg} / \mathrm{dl}$ [month 4], $p<0.001)$ than in the free-combination group (from $4.17 \pm 0.31$ vs. $4.26 \pm 0.28$ to $4.10 \pm 0.19 \mathrm{mg} / \mathrm{dl}$, non-significant difference). Three patients in the FDTC group discontinued the study (two for ankle edema and one for cough) as did two patients in the free-combination group (one for hypotension and one for dizziness).

\section{DISCUSSION}

In our study, performed in patients with moderate hypertension who did not achieve blood pressure targets using dual fixed-combination therapy with a RAAS blocker and a diuretic, a significant improvement in blood pressure lowering and control was observed after switching to an FDTC therapy with perindopril/ indapamide/amlodipine at doses ranging from $5 / 1.25 / 5$ to $10 / 2.5 / 10 \mathrm{mg}$ once daily. FDTC therapy was more effective than free-combination therapy in reducing blood pressure values after the first month of treatment. In addition, 


\section{FCT $\square$ TFC}

$24 \mathrm{~h}$ average $B P$ values
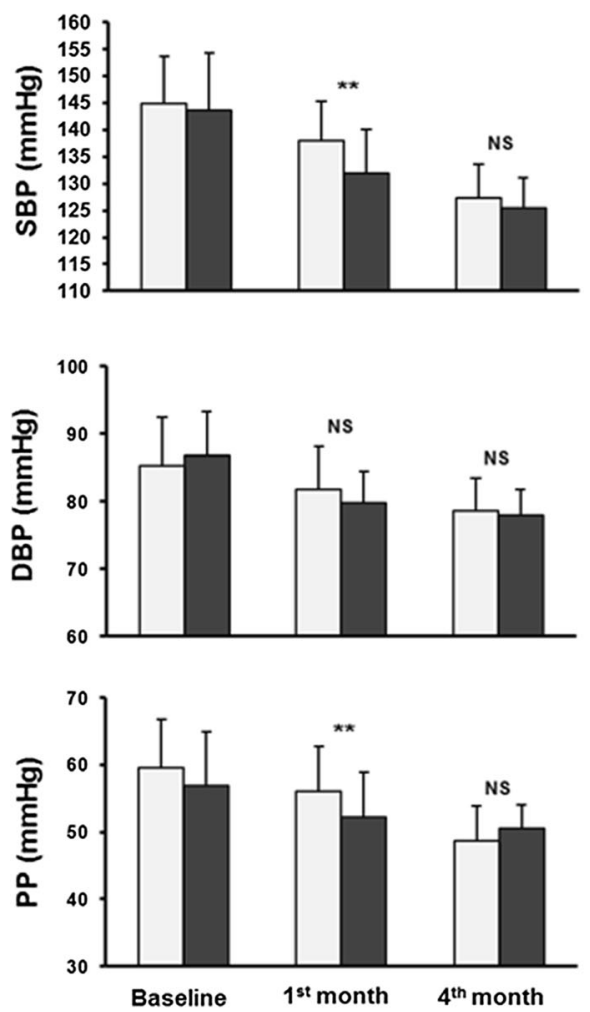

Diurnal BP values
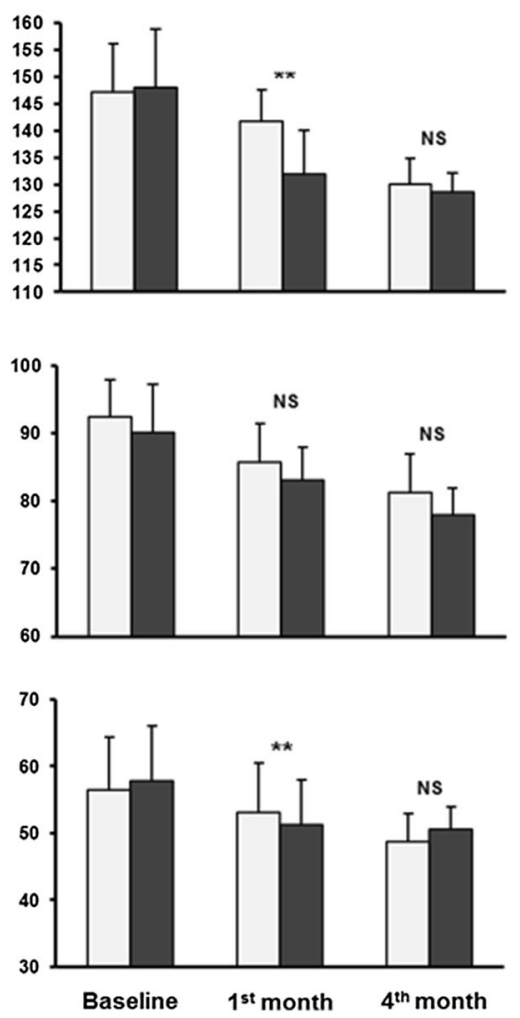

Nocturnal BP values
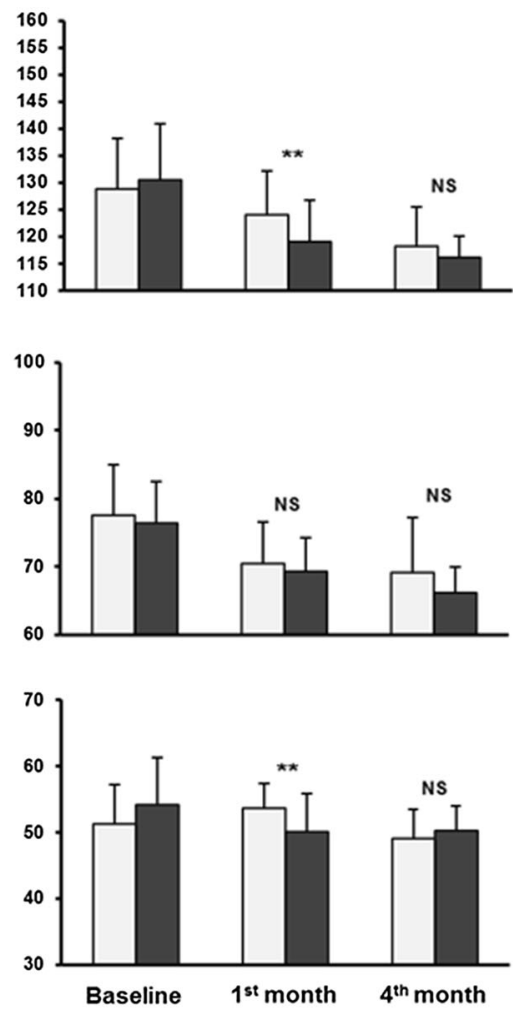

Fig. 1 Changes in 24-h ambulatory systolic blood pressure (SBP), diastolic blood pressure (DBP), and pulse pressure (PP) with free-combination therapy (FCT) and fixed-dose triple combination (FDTC) therapy; NS not significant,
${ }^{* *} p<0.05$ vs. FCT; all values at 1 st and 4 th month are statistically significant vs. baseline $(p<0.05)$. Values are presented as means

ABPM pulse pressure and nighttime blood pressure. The increase of pulse pressure (the pulsatile component of blood pressure) is an age-related phenomenon and the common belief is that it is an indicator of large artery stiffness [18] and an established marker of cardiovascular risk in different clinical settings $[19,20]$. High pulse pressure may derive both from a rise in systolic values and from a decrease in diastolic values. In our study, the systolic component was prominent, as diastolic blood pressure remained unchanged or even increased slightly with increasing pulse pressure.

Nocturnal hypertension is a common complication of essential hypertension and well known to be associated with a worse cardiovascular risk and prognosis $[21,22]$. Nocturnal 
hypertension can be treated with several approaches that include lifestyle changes-such as sodium restriction and potassium supplementation-and pharmacotherapy, primarily through the use of bedtime dosing of antihypertensive agents [23]. In our study, a drop in nighttime blood pressure values was found during FDTC treatment without any evening administration of drugs, suggesting that the drugs tested in this formulation had a long half-life and an antihypertensive effect sustained during the $24 \mathrm{~h}$. Efficacy of the various classes of antihypertensive agents for restoring normal dipping is not well studied. However, the RAAS blockers, the calcium antagonists, and diuretics appear to be superior to $\alpha$ - and $\beta$-blockers $[24,25]$. In elderly hypertensives with systolic hypertension, dihydropyridines and thiazide diuretics lowered daytime blood pressure to a greater extent than $\beta$-blocking drugs; perindopril had the greatest effect on nocturnal blood pressure, whereas atenolol did not show any effect [26]. However, the role of different classes of antihypertensive drugs should be assessed more in detail in clinical trials, as some drugs may accentuate nocturnal dipping, others may blunt the normal nocturnal decrease in blood pressure, and others have no effect [27].

The European hypertension guidelines recommend combining blood pressure-lowering drugs [6], particularly using fixed-drug combinations in a single pill. This suggestion may offer several advantages over free-drug combinations, e.g., better compliance and an increased adherence to the prescribed regimen [28]. This leads to an increased lowering effect and to a more rapid achievement of the target [29], which has been shown to correlate with improvement in clinical outcome and with decreased incidence of cardiovascular morbidity and mortality [30]. On the other hand, beyond the therapeutic class effects, the specific properties of perindopril, indapamide, and amlodipine suggest additional blood pressure-lowering effects relative to other antihypertensive drugs $[31,32]$. The combination of perindopril plus indapamide has been shown to improve vascular endothelial function, arterial stiffness, and small artery remodelling [33], thereby reducing pressor wave reflections during systole [34].

Furthermore-unlike other ACEIs such as enalapril in the PICXEL study [35] or ARBsperindopril plus indapamide sustained release in the HYVET trial [36], perindopril in fixed combination with indapamide in the ADVANCE trial [34], and a combination of perindopril and amlodipine in the blood pressure-lowering arm of the ASCOT trial [37] have all shown additional and significant mortality benefits. However, long-term studies are mandatory to confirm that predicted improvements in organ protection and reduced mortality rates can be extended to the FDTC tested in our study.

A possible criticism of our results may result from the lack of a between-group difference in blood pressure-lowering effects after 4 months of treatment. This lack of effect is not surprising, as the drugs tested in the free-combination therapy group had a wide and proven efficacy in lowering blood pressure over the long term [6]. On the other hand, the greater blood pressure-lowering effect of FDTC relative to free-combination therapy observed in the short term may in part be due to the different diuretic used in the two groups. In fact, slow-release indapamide (used in our study in $75 \%$ of hypertensive patients in the FDTC therapy group) seems to have a greater antihypertensive potency than hydrochlorothiazide. As demonstrated in a recent systematic review and meta-analysis of head-to-head comparison studies, which included additional analyses [38], at commonly used doses indapamide lowers SBP more than hydrochlorothiazide, without any evidence of increased metabolic adverse effects, and with no significant effects on serum potassium. In general, thiazide diuretics lower BP via decreased peripheral arterial resistance through unknown mechanisms $[5,6]$, while indapamide is known to have a direct vasodilator effect from vasopressor inhibition and decreased inward flow of calcium ions in vascular smooth muscle [39]. Finally, we speculate that the better lowering effect of FDTC therapy may be due to a potentially synergistic antihypertensive effect of the included drugs in optimal combination, leading to an effect greater than the usual additive one [40]. 


\section{Study Limitations}

Our study was monocentric, not blinded, and limited by its short treatment period and relatively small-sized treatment groups. Tolerability findings suggest that clinicians could adopt this new means of improving hypertension management. However, a large-scale study may be needed to determine long-term safety and clinical outcomes of triple fixed-combination over free-combination therapy.

\section{CONCLUSION}

Our study results show the fixed-dose triple combination therapy of perindopril/indapamide/amlodipine was effective in reducing systolic and pulse pressure in patients with moderate hypertension uncontrolled by dual fixed-combination therapy. No major concern with FDTC tolerability emerged in this study. Our findings provide support for clinicians in choosing a fixed-dose triple combination over a free-combination of three antihypertensives including a RAAS inhibitor, a diuretic, and a calcium channel blocker.

\section{ACKNOWLEDGEMENTS}

No funding or sponsorship was received for this study. Article processing charges and open access fee for this article were funded by Servier.

We thank Gayle Robins, independent medical writer, who provided editorial assistance and journal styling services prior to submission on behalf of Springer Healthcare Communications. Editorial services were funded by Servier.

All named authors meet the International Committee of Medical Journal Editors (ICMJE) criteria for authorship for this manuscript, take responsibility for the integrity of the work as a whole, and have given final approval to the version to be published.

Disclosures. Alberto Mazza, Salvatore Lenti, Laura Schiavon, Antonella Paola Sacco, Fabio
Dell'Avvocata, Gianluca Rigatelli, and Emilio Ramazzina have nothing to disclose.

Compliance with Ethics Guidelines. The study protocol was approved by local ethics committee and institutional review boards, and procedures were followed in accordance with ICH Harmonized Tripartite Guidelines for Good Clinical Practice and with the Helsinki Declaration of 1964, as revised in 2013. Informed consent was obtained from all patients for being included in this study.

Data Availability. The datasets generated and/or analyzed during the current study are available from the corresponding author on reasonable request.

Open Access. This article is distributed under the terms of the Creative Commons Attribution-NonCommercial 4.0 International License (http://creativecommons.org/licenses/ by-nc/4.0/), which permits any noncommercial use, distribution, and reproduction in any medium, provided you give appropriate credit to the original author(s) and the source, provide a link to the Creative Commons license, and indicate if changes were made.

\section{REFERENCES}

1. Chow CK, Teo KK, Rangarajan S, et al. Prevalence, awareness, treatment, and control of hypertension in rural and urban communities in high-, middle-, and low-income countries. JAMA. 2013;310:959-68.

2. Jamerson K, Weber MA, Bakris GL, et al. Benazepril plus amlodipine or hydrochlorothiazide for hypertension in high-risk patients. $\mathrm{N}$ Engl J Med. 2008;359:2417-28.

3. Düsing R, Waeber B, Destro M, Santos Maia C, Brunel P. Triple-combination therapy in the treatment of hypertension: a review of the evidence. J Hum Hypertens. 2017. doi: 10.1038/jhh.2017.5.

4. Chow CK, Thakkar J, Bennett A, et al. Quarter-dose quadruple combination therapy for initial treatment of hypertension: placebo-controlled, crossover, randomised trial and systematic review. Lancet. 2017;389:1035-42. 
5. James PA, Oparil S, Carter BL, et al. 2014 evidence-based guideline for the management of high blood pressure in adults. Report from the panel members appointed to the Eighth Joint National Committee (JNC 8). JAMA. 2014;311:507-20.

6. Mancia G, Fagard R, Narkiewicz K, et al. 2013 practice guidelines for the management of arterial hypertension of the European Society of Hypertension (ESH) and the European Society of Cardiology (ESC): ESH/ESC Task Force for the Management of Arterial Hypertension. J Hypertens. 2013;31:1925-38.

7. Gupta AK, Arshad S, Poulter NR. Compliance, safety, and effectiveness of fixed-dose combinations of antihypertensive agents. A meta-analysis. Hypertension. 2010;55:399-407.

8. Xie L, Frech-Tamas F, Marrett E, Baser O. A medication adherence and persistence comparison of hypertensive patients treated with single-, doubleand triple-pill combination therapy. Curr Med Res Opin. 2014;30:2415-22.

9. Mazzaglia G, Ambrosioni E, Alacqua $\mathrm{M}$, et al. Adherence to antihypertensive medications and cardiovascular morbidity among newly diagnosed hypertensive patients. Hypertens J Am Heart Assoc. 2009;120:1598-605.

10. Yang W, Chang J, Kahler KH, Fellers T, Orloff J. Evaluation of compliance and health care utilization in patients treated with single pill vs. free combination antihypertensives. Curr Med Res Opin. 2010;26:2065-76.

11. Zeng F, Patel BV, Andrews L, Frech-Tamas F, Rudolph AE. Adherence and persistence of single-pill $\mathrm{ARB} / \mathrm{CCB}$ combination therapy compared to multiple pill ARB/CCB regimens. Curr Med Res Opin. 2010;26(12):2877-87.

12. Neutel JM. Prescribing patterns in hypertension: emerging role of fixed dose combinations for attaining BP goals in hypertensive patients. Curr Med Res Opin. 2008;24(8):2389-401.

13. Palatini $P$, Frigo $G$, Bertolo $\mathrm{O}$, Roman $\mathrm{E}$, Da Cortà $\mathrm{R}$, Winnicki M. Validation of the A\&D TM-2430 device for ambulatory blood pressure monitoring and evaluation of performance according to subject's characteristics. Blood Press Monit. 1998;3:255-60.

14. Mazzachi BC, Peake MJ, Ehrhardt V. Reference range and method comparison studies for enzymatic and Jaffé creatinine assays in plasma and serum and early morning urine. Clin Lab. 2000;46:53-5.
15. O'Brien E, Parati G, Stergiou G, et al. European Society of Hypertension position paper on ambulatory blood pressure monitoring. J Hypertens. 2013;31:1731-68.

16. Conen D, Bamberg F. Noninvasive 24-h ambulatory blood pressure and cardiovascular disease: a systematic review and meta-analysis. J Hypertens. 2008;26:1290-9.

17. Zaninelli A, Parati G, Cricelli C, et al. Office and 24-h ambulatory blood pressure control by treatment in general practice: the 'Monitoraggio della pressione ARteriosa nella medicina TErritoriale' study. J Hypertens. 2010;28:910-7.

18. Steppan J, Barodka V, Berkowitz DE, Nyhan D. Vascular stiffness and increased pulse pressure in the aging cardiovascular system. Cardiol Res Pract. 2011;263585:1-8. doi:10.4061/2011/263585.

19. Mazza A, Pessina AC, Tikhonoff V, Pavei A, Privato G, Casiglia E. Pulse pressure: an independent predictor of coronary and stroke mortality in elderly females from the general population. Blood Press. 2001;10:205-11.

20. Casiglia E, Tikhonoff V, Mazza A, Piccoli A, Pessina AC. Pulse pressure and coronary mortality in elderly men and women from general population. J Hum Hypertens. 2002;15:611-20.

21. Tsioufis C, Andrikou I, Thomopoulos C, Syrseloudis D, Ster-giou G, Stefanadis C. Increased nighttime blood pressure or nondipping profile for prediction of cardiovascular outcomes. J Hum Hypertens. 2011;25:281-93.

22. Cuspidi C, Giudici V, Negri F, Sala C. Nocturnal nondipping and left ventricular hypertrophy in hypertension: an updated review. Expert Rev Cardiovasc Ther. 2010;8:781-92.

23. Zeng J, Jia M, Ran $\mathrm{H}$, et al. Fixed-combination of amlodipine and diuretic chronotherapy in the treatment of essential hypertension: improved blood pressure control with bedtime dosing-a multicenter, open-label randomized study. Hypertens Res. 2011;34:767-72.

24. Hermida RC, Ayala DE, Fernandez JR, et al. Circadian rhythms in blood pressure regulation and optimization of hypertension treatment with ACE inhibitor and ARB medications. Am J Hypertens. 2011;24:383-91.

25. Hoshide Y, Kario K, Schwartz JE, Hoshide S, Pickering TG, Shimada K. Incomplete benefit of antihypertensive therapy on stroke reduction in older hypertensives with abnormal nocturnal blood pressure dipping (extreme-dippers and reverse-dippers). Am J Hypertens. 2002;15:844-50. 
26. Morgan TO, Anderson A. Different drug classes have variable effects on blood pressure depending on the time of day. Am J Hypertens. 2003;16:46-50.

27. Giles TD. Circadian rhythm of blood pressure and the relation to cardiovascular events. J Hypertens. 2006;24(suppl 2):S11-6.

28. Mallat SG, Tanios BY, Itani HS, Lotfi T, Akl EA. Free versus fixed combination antihypertensive therapy for essential arterial hypertension: a systematic review and meta-analysis. PLoS One. 2016;11(8):e0161285.

29. Weber MA, Julius S, Kjeldsen SE, et al. Blood pressure dependent and independent effects of antihypertensive treatment on clinical events in the VALUE trial. Lancet. 2004;363(9426):2049-51.

30. Scotti L, Baio G, Merlino L, Cesana G, Mancia G, Corrao G. Cost-effectiveness of enhancing adherence to therapy with blood pressure-lowering drugs in the setting of primary cardiovascular prevention. Value Health. 2013;16(2):318-24.

31. Williams B, Lacy PS, Thom SM, et al. Differential impact of blood pressure-lowering drugs on central aortic pressure and clinical outcomes: principal results of the conduit artery function evaluation (CAFE) study. Circulation. 2006;113(9):1213-25.

32. London GM, Asmar RG, O'Rourke M, Safar ME, on behalf of the REASON Investigators. Mechanism(s) of selective systolic blood pressure reduction after a low-dose combination of perindopril/ indapamide in hypertensive subjects: comparison with atenolol. J Am Coll Cardiol. 2004;43:92-9.

33. Ghiadoni L, Magagna A, Kardasz I, Taddei S, Salvetti A. Fixed dose combination of perindopril and indapamide improves peripheral vascular function in essential hypertensive patients. Am J Hypertens. 2009;22(5):506-12.
34. Patel A, MacMahon S, Chalmers J, et al. Effects of a fixed combination of perindopril and indapamide on macrovascular and microvascular outcomes in patients with type 2 diabetes mellitus (the ADVANCE trial): a randomised controlled trial. Lancet. 2007;370(9590):829-40.

35. Dahlof B, Gosse P, Gueret P, et al. Perindopril/indapamide combination more effective than enalapril in reducing blood pressure and left ventricular mass: the PICXEL study. J Hypertens. 2005;23(11):2063-70.

36. Peters R, Beckett N, Burch L, et al. The effect of treatment based on a diuretic (indapamide) \pm ACE inhibitor (perindopril) on fractures in the Hypertension in the Very Elderly Trial (HYVET). Age Ageing. 2010;39(5):609-16.

37. Dahlof B, Sever PS, Poulter NR, et al. Prevention of cardiovascular events with an antihypertensive regimen of amlodipine adding perindopril as required versus atenolol adding bendroflumethiazide as required, in the Anglo-Scandinavian cardiac outcomes trial-blood pressure lowering arm (ASCOT-BPLA): a multicentre randomised controlled trial. Lancet. 2005;366:895-906.

38. Roush GC, Ernst ME, Kostis JB, Tandon S, Sica DA. Head-to-head comparisons of hydrochlorothiazide with indapamide and chlorthalidone: antihypertensive and metabolic effects. Hypertension. 2015;65(5):1041-6.

39. Campbell DB. The possible mode of action of indapamide: a review. Curr Med Res Opin. 1983;8(suppl 3):9-24.

40. Stanton T, Reid JL. Fixed dose combination therapy in the treatment of hypertension. J Hum Hypertens. 2002;16(2):75-8. 